\title{
Das Verhalten des Lecithins zu fettspaltenden Fermenten.
}

\section{Von}

\author{
C. Schumoff-Simanowski und N. Sieber. ${ }^{1}$ )
}

(Aus dem chemischen Laboratorium des Kaiserl. Instituts für experimentelle Medizin in St. Petersburg.)

(Der Redaktion zugegangen am 10. August 1906.)

Die Frage, ob die fettspaltenden Fermente oder Enzyme unter einander identisch sind, ist bis heute noch nicht entschieden. Es sind im Gegenteil eine Reihe von Tatsachen bekannt, welche gegen die vermeintliche Identität zwischen Lipase, dem fettspaltenden Enzym des Blutes, resp. Serums einerseits und Steapsin, dem fettspaltenden Ferment des Pankreas, resp. seines Saftes, zu sprechen scheinen. Was das fettspaltende Ferment des Magens anbetrifft, so sind unsere diesbezüglichen Kenntnisse erst durch die in den letzten Jahren von Volhard ${ }^{2}$ ) und seinen Mitarbeitern A. Zinsser, ${ }^{3}$ ) W.Stade ${ }^{4}$ ) und A. Fro $\mathrm{mme}^{5}$ ) über dessen Wirkung im allgemeinen ausgeführten Untersuchungen bereichert worden; in bezug aber auf seine Identität mit anderen fettspaltenden Fermenten kann fürs erste nichts Positives geäußert werden. Gelegentlich einer Untersuchung über die Lecithine verschiedenen Ursprungs, sowie über die ihnen nahe

1) Vorliegende Untersuchung wurde noch zu Lebzeiten und gemeinschaftlich mit meiner unvergeßlichen, leider $z u$ früh verstorbenen Schwester, Frau Dr. Schumoff-Simanowski, vor 11/8 Jahren begonnen und von mir zu Ende geführt. Äußerer Umstände wegen erscheint die Arbeit so spät im Drucke.

N. Sieber.

2) Beiträge z. chem. Physiol. u. Pathol. v. Hofmeister, Bd. VII, S. 1, 2, 3; München. med. Wochenschr. 1900, Nr. 5 u. 6 ; Zeitschrift für klin. Med., Bd. XLII, Heft 5 u. 6, 1901; ebenda, Bd. XLIII, Heft 5 u. 6.

3) Beitr. z. chem. Physiol. v. Hofmeister, Bd. VII, S. 31.

4) Ibid., Bd. III, S. 291.

5) Ibid., Bd. VII, S. 51. 
stehenden phosphorhaltigen Substanzen und über die hydrolytischen Spaltungsprodukte dieser und jener Verbindungen berührten wir auch die Frage, ob die genannten äußerst komplizierten Verbindungen imstande sind, durch die lipolytischen Fermente resp. Enzyme zerlegt zu werden, und wie weit diese Spaltung durch Fermente eventuell vor sich gehen kann. Zum Vergleich wurden parallele Versuche über die Spaltung des Lecithins mittels Säuren und Alkalien aufgestellt, um den zeitlichen Verlauf und die Intensität der Zersetzungen bei den verschiedenartigen Spaltungen vergleichen zu können.

Das Lecithin, mit welchem wir unsere Versuche anstellten, wurde von uns aus Eigelb dargestellt, außerdem verwendeten wir zum Vergleich das käufliche Präparat von C. A.F. Kahlbaum. Was die Spaltbarkeit anbetrifft, so haben beide Präparate keine merklichen Unterschiede gezeigt. Das Lecithin wurde in Form einer wässerigen Emulsion zu den Spaltungsversuchen verwendet und zwar enthielt diese 2, höchstens 30\% Lecithin und wurde durch Erwärmen und fortwährendes Schütteln hergestellt. Die Versuchsanordnung war folgende. Die frisch dargestellte Lecithinemulsion wurde mit sterilen Pipetten in der Menge von $10-5 \mathrm{ccm}$ in sterilisierte Erlenmeyersche Kölbchen, welche mit angeschliffenen Glaspfropfen versehen waren, übertragen und daraufhin vermittelst einer anderen sterilisierten Pipette die Fermentlösung hineingebracht. Es wurden stets zwei parallele und doppelte Versuche angestellt, außerdem 6 Kontrollkölbchen aufgestellt. Diese letzteren wurden in folgender Weise ausgenützt. Zwei von ihnen wurden sofort mit $1 / 80 \mathrm{n}-\mathrm{KHO}$ titriert und zwar das eine nach Erwärmen und Zusatz von 95\% igem säurefreie Spiritus, das andere ohne jegliche Vorbehandlung; als Indikator diente hierbei Phenolphtalein. Diese Titration stellte die Reaktion des Gemisches vor Einwirkung des Fermentes fest. Die übrigen 4 Kontrollkölbchen enthielten die gleichen Mengen Lecithinemulsion und Fermentlösung wie oben, doch war das zugesetzte Ferment vorher aufgekocht, um die fermentative Einwirkung des Hauptversuches zu kontrollieren. Von den 4 Kontrollkölbchen wurden 2 sofort titriert und zwar wieder das eine ohne jegliche Vorbehandlung, das andere nach Zusatz von 20\% igem Spiritus und Erwärmen. 
Tabelle

Wirkung des Pankreas-

Säuregrad in Kubikzentimetern der zur

\begin{tabular}{|c|c|c|c|c|}
\hline \multirow{2}{*}{ Versuchsanordnung } & \multicolumn{2}{|c|}{$\begin{array}{l}\text { Reaktion des Gemisches } \\
\text { vor der Einwirkung } \\
\text { des Fermentes }\end{array}$} & \multicolumn{2}{|c|}{$\begin{array}{c}\text { Reaktion des Gemisches } \\
\text { nach Zusatz von auf } 72^{\circ} \\
\text { erwärmtem Ferment }\end{array}$} \\
\hline & $\begin{array}{l}\text { Titration in } \\
\text { wässeriger } \\
\text { Lösung }\end{array}$ & \begin{tabular}{|} 
Titration in \\
alkoholischer \\
Lösung
\end{tabular} & $\begin{array}{l}\text { Titration in } \\
\text { wässeriger } \\
\text { Lösung }\end{array}$ & $\begin{array}{l}\text { Titration in } \\
\text { alkoholischer } \\
\text { Lösung }\end{array}$ \\
\hline $5 \mathrm{ccm}$ Lecithinemulsion & 3,0 & 7,3 & 2,9 & 7,4 \\
\hline$+1 \mathrm{ccm}$ Pankreassaft $A$ & 3,2 & 7,4 & 3,1 & 7,3 \\
\hline $5 \mathrm{ccm}$ Lecithinemulsion & 5,8 & 9,1 & 5,9 & 9,0 \\
\hline + 2 ccm Pankreassaft $\mathbf{A}$ & 6,0 & 9,0 & 6,0 & 9,0 \\
\hline $5 \mathrm{ccm}$ Lecithinemulsion & 1,3 & 4,3 & 1,4 & 4,2 \\
\hline$+1 \mathrm{ccm}$ Pankreassaft $B$ & 1,5 & 3,5 & 1,5 & 3,4 \\
\hline $5 \mathrm{ccm}$ Lecithinemulsion & 3,2 & 5,5 & 3,2 & 5,4 \\
\hline$+2 \mathrm{ccm}$ Pankreassaft B & 3,1 & 5,4 & 3,1 & 5,3 \\
\hline $5 \mathrm{ccm}$ Lecithinemulsion & 2,6 & 4,4 & 2,5 & 4,3 \\
\hline$+2 \mathrm{ccm}$ Pankreassaft $\mathrm{C}$ & 2,8 & 4,4 & 2,7 & 4,3 \\
\hline $5 \mathrm{ccm}$ Lecithinemulsion & 3,0 & 7,0 & 2,8 & 7,1 \\
\hline wärmter Pankreassaft A & 2,8 & 6,9 & 2,9 & 6,8 \\
\hline $5 \mathrm{ccm}$ Lecithinemulsion & 2,5 & 4,5 & 2,4 & 4,4 \\
\hline wärmter Pankreassaft $\mathrm{C}$ & 2,6 & 4,4 & 2,6 & 4,3 \\
\hline $\begin{array}{l}5 \mathrm{ccm} \text { Lecithinemulsion } \\
+2 \mathrm{ccm} \text { Auszug aus }\end{array}$ & 2,4 & 4,3 & 2,4 & 4,4 \\
\hline dem Pankreas & 2,5 & 4,4 & 2,4 & 4,5 \\
\hline $\begin{array}{l}5 \mathrm{ccm} \text { Lecithinemulsion } \\
+5 \mathrm{ccm} \text { Auszug aus }\end{array}$ & 3,2 & 4,8 & 3,2 & 4,7 \\
\hline dem Pankreas & 3,1 & 4,7 & 3,1 & 4,7 \\
\hline $\begin{array}{c}5 \mathrm{ccm} \text { Lecithinemulsion } \\
+2 \mathrm{ccm} \text { mit Kinase }\end{array}$ & 2,3 & 4,5 & 2,3 & 4,5 \\
\hline aktiviertemPankreassaft B & 2,5 & 4,5 & 2,5 & 4,5 \\
\hline $\begin{array}{l}5 \mathrm{ccm} \text { Lecithinemulsion } \\
+2 \mathrm{ccm} \text { mit Kinase }\end{array}$ & 2,1 & 4,3 & 2,0 & 4,2 \\
\hline $\begin{array}{l}\text { aktiviertem und auf } 72^{\circ} \\
\text { erwärmtem Pankreassaft }\end{array}$ & 2,2 & 4,4 & 2,1 & 4,4 \\
\hline
\end{tabular}


Nr. I.

steapsins auf Lecithin.

Neutralisation gebrauchten $1 / 20-\mathrm{KHO}$.

\begin{tabular}{|c|c|c|c|c|c|}
\hline \multicolumn{2}{|c|}{$\begin{array}{l}\text { Reaktion des Gemisches } \\
\text { mit auf } 72^{\circ} \text { erwärmtem } \\
\text { Ferment nach } 24 \text { st. Ver- } \\
\text { weilen im Thermostaten }\end{array}$} & \multicolumn{2}{|c|}{$\begin{array}{l}\text { Reaktion des Gemisches } \\
\text { nach 24stündigem Ver- } \\
\text { weilen im Thermostaten }\end{array}$} & \multicolumn{2}{|c|}{$\begin{array}{c}\text { Aciditätszuwachs in } \\
\text { Kubikzentimetern }{ }^{1} / 20-\mathrm{KHO} \\
\text { ausgedrückt }\end{array}$} \\
\hline $\begin{array}{c}\text { Titration in } \\
\text { wässeriger } \\
\text { Lösung }\end{array}$ & $\mid \begin{array}{c}\text { Titration in } \\
\text { alkoholischer } \\
\text { Lösung }\end{array}$ & $\begin{array}{l}\text { Titration in } \\
\text { wässeriger } \\
\text { Lösung }\end{array}$ & $\begin{array}{l}\text { Titration in } \\
\text { alkoholischer } \\
\text { Lösung }\end{array}$ & $\begin{array}{c}\text { Titration in } \\
\text { wässeriger } \\
\text { Lösung }\end{array}$ & $\begin{array}{l}\text { Titration in } \\
\text { alkoholischer } \\
\text { Lösung }\end{array}$ \\
\hline 3,1 & 7,3 & 4,8 & 9,4 & 1,8 & 2,1 \\
\hline 3,1 & 7,3 & 5,2 & 9,4 & 2,0 & 2,0 \\
\hline 5,8 & 8,9 & 9,4 & 18,5 & 3,6 & 9,4 \\
\hline 5,9 & 9,0 & 9,8 & 18,4 & 3,8 & 9,4 \\
\hline 1,3 & 4,2 & 2,65 & 5,82 & 1,35 & $\mathbf{1 , 5 2}$ \\
\hline 1,5 & 3,3 & 3,0 & 5,5 & 1,5 & 2,0 \\
\hline 3,2 & 5,4 & 6,3 & 9,5 & 3,1 & 4,0 \\
\hline 3,2 & 5,4 & 6,3 & 9,6 & 3,2 & 4,2 \\
\hline 2,2 & 4,5 & 5,3 & 7,5 & 2,7 & 3,1 \\
\hline 2,6 & 4,4 & 5,7 & 7,5 & 2,0 & $\mathbf{3 , 1}$ \\
\hline 2,9 & 7,0 & 2,9 & 7,0 & 0 & 0 \\
\hline 2,8 & 6,8 & 2,8 & 6,9 & 0 & 0 \\
\hline $2, \overline{5}$ & $4, \tilde{\partial}$ & 2,5 & 4,6 & 0 & 0 \\
\hline 2,6 & 4,4 & 2,5 & 4,4 & 0 & 0 \\
\hline 2,4 & 4,3 & 3,7 & 5,8 & 1,3 & 1,5 \\
\hline 2,5 & 4,4 & 3,9 & 5,7 & 1,4 & 1,3 \\
\hline 3,1 & 4,8 & 5,7 & 7,8 & 2,5 & 3,0 \\
\hline 3,1 & 4,8 & 5,7 & 7,9 & 2,6 & 3,2 \\
\hline 2,3 & 4,5 & 5,8 & 8,4 & $\mathbf{3 , 5}$ & 3,9 \\
\hline 2,5 & 4,5 & 6,0 & 8,3 & $\mathbf{3 , 5}$ & 3,8 \\
\hline 2,0 & 4,3 & 2,0 & 4,2 & 0 & 0 \\
\hline 2,2 & 4,3 & 2,1 & 4,3 & $\begin{array}{c}0 \\
0\end{array}$ & $\begin{array}{l}\text { hentica } \mathbf{0} \\
\text { te } 5 / 25 / 157: 3\end{array}$ \\
\hline
\end{tabular}


Die 2 letzten Kontrollkölbchen mit erwärmtem Ferment wurden ebensolange wie die Hauptversuchskölbchen in Thermostaten stehen gelassen und nachher zu gleicher Zeit mit 1/20 n-KHOLösung titriert und zwar wiederum das eine ohne Vorbehandlung, das andere nach Zusatz von $95 \%$ igem Spiritus und Erwärmen. Zur Aufklärung der uns interessierenden Frage nach der Zersetzung des Lecithins durch fettspaltende Enzyme wurden in erster Linie Versuche mit dem Steapsin des Pankreas resp. des Pankreassaftes, dem energischsten Representanten der lipolytischen Funktion, angestellt. Den Pankreassaft erhielten wir dank der Liebenswürdigkeit von Professor J. Pawlow und seines Assistenten am physiologischen Laboratorium der Kaiserlichen Militärmedicinischen Akademie, Dr. W. B oldyre w, wofür wir uns verpflichtet fühlen, den genannten Herren an dieser Stelle unseren herzlichsten Dank auszusprechen. Außer dem Pankreassafte wurden auch Extrakte aus der Drüse, sowie das käufliche Pankreatin zu den Versuchen verwendet. Die verschiedenen Pankreaspräparate resp. Pankreassäfte verhielten sich, was ihre Wirkung auf Lecithin anbetrifft, nur graduell verschieden, d. h., einige verursachten stärkere, andere aber schwächere Säurebildung, was sich durch eine größere oder geringere Menge der zum Titrieren bis zu neutraler Reaktion erforderlichen Lauge kund gab und was mit der Aktivität des verwendeten Präparates im Zusammenhange stand. Übrigens illustriert obenstehende Tabelle, welche nur einen Teil des Versuchmaterials enthält, die erzielten Resultate in Zahlen am besten.

Aus der oben angeführten Tabelle ist $z u$ ersehen, daß das Steapsin des Pankreas und seines Saftes imstande ist, das komplexe Molekül des Lecithins zu spalten und zwar Fettsäuren daraus in Freiheit zu setzen, was sich durch Anwachsen der Acidität der nach Einwirkung des Fermentes titrierten Lösung zu erkennen gibt. Nachdem die Frage der Lecithinzerlegung mittels fettspaltenden Pankreasfermentes prinzipiell und zwar positiv entschieden war, mußte man die Intensität, mit welcher der Prozeß vor sich gehen kann, bestimmen. Durch diesbezügliche Versuche konnte festgestellt werden, daß der Zuwachs der Acidität mit der Fermentmenge und fermentativen Kraft 
wächst, da die fermentative Kraft jedes Saftes in jedem Versuche durch parallele Nebenversuche mittels künstlicher Fette, wie Monobutyrin und Äthylbutyrat, noch kontrolliert wurde.

Außer dem eben angeführten wurden andere Versuche gemacht, um die quantitativen Verhältnisse der Lecithinspaltung zu erforschen und zwar nach der vor kurzem ausgearbeiteten Methode von Volhard resp. Dr. W. Stade, ${ }^{1}$ ) welche von Dr. Zinsser ${ }^{2}$ ) und Dr. A. Fromme ${ }^{3}$ ) mit gutem Erfolge zur Untersuchung der fettspaltenden Kraft des Magensteapsins angewandt worden ist. Obgleich wir mit dieser Methode nicht viele Versuche angestellt haben, so scheint sie uns doch praktisch und leicht ausführbar zu sein und gute Resultate zu liefern. Da wir die Methode hier nicht ausführlich beschreiben können, so verweisen wir wegen der einigen dabei zu berücksichtigenden Details auf die oben erwähnten Autoren. Kurz ausgedrückt besteht die Methode der quantitativen Fettzersetzung in zweimaliger Titration des Fettverdauungsgemisches: durch die erste Titration stellt man die Menge der durch Fermentwirkung gebildeten Säure fest, durch die zweite aber, welche nach Verseifung eines aliquoten Teils des ätherischen Auszuges aus dem Fettverdauungsgemische mittels titrierter Lauge vorgenommen wird, bestimmt man die Menge der Säure des nicht durch Ferment zersetzten Fettes resp. in unserem Falle des Lecithins. Aus den Zahlen der ersten und zweiten Titration berechnet man sodann das Resultat der Fettspaltung in Prozenten.

Die für Lecithinzersetzung nach dieser Methode erzielten Ergebnisse sind in der nachfolgenden Tabelle zusammengestellt.

Wir ersehen aus den in der Tabelle angeführten Zahlen, daß die Menge des zersetzten Lecithins je nach der Wirksamkeit des Fermentes große Schwankungen zeigt, nämlich in Prozenten ausgedrückt 12,3 bis $45,2 \%$.
1) 1. c.
2) $1 . \mathrm{c}$.
s) $1 . \mathrm{c}$. 
Tabelle Nr. II.

Zersetzung des Lecithins durch Pankreassteapsin in Prozenten.

\begin{tabular}{c|c|c|c|c|c}
\hline \hline & $\begin{array}{c}\text { Dauer } \\
\text { der } \\
\text { Ferment- } \\
\text { wirkung } \\
\text { in } \\
\text { Stunden }\end{array}$ & $\begin{array}{c}\text { I. Titra- } \\
\text { tion durch } \\
\text { Ferment } \\
\text { abgespalt. } \\
\text { Fett- } \\
\text { säuren }\end{array}$ & $\begin{array}{c}\text { II. Titra- } \\
\text { tion durch } \\
\text { Ver- } \\
\text { seifung } \\
\text { abgespalt. } \\
\text { Fett- } \\
\text { säuren }\end{array}$ & $\begin{array}{c}\text { Summe } \\
\text { der } \\
\text { Fett- } \\
\text { säuren } \\
\text { in } \begin{array}{c}\text { 50 ccm } \\
\text { Âther }\end{array}\end{array}$ & $\begin{array}{c}\text { Prozent } \\
\text { der durch } \\
\text { Ferment } \\
\text { abgespalt. } \\
\text { Fett- } \\
\text { säuren }\end{array}$ \\
\hline $\begin{array}{c}\text { 5 ccm Lecithin- } \\
\text { emulsion +5 ccm }\end{array}$ & 24 & 4,4 & 9,4 & 13,8 & 31,88 \\
Pankreassteapsin & 24 & 11,5 & 13,9 & 25,4 & 45,2 \\
$\diamond$ & 24 & 4,17 & 12,13 & 16,3 & 25,6 \\
& 24 & 2,11 & 9,09 & 12,2 & 16,5 \\
& 24 & 1,03 & 7,07 & 8,1 & 12,8
\end{tabular}

Zersetzung des Lecithins durch Magensteapsin.

Das Magensteapsin wurde nach Angaben von Volhard ${ }^{1}$ ) und Fromme $\mathrm{m}^{2}$ ) aus dem Magen eines eben getöteten Hundes gewonnen. Der Magen wurde gründlich ausgewaschen, mit einer gleichen Gewichtsmenge wasserfreien Glycerins übergossen und während 5 Tage im Thermostaten stehen gelassen, während das Gemisch oft umgeschüttelt wurde. Die erste Probe zum Nachweis des Steapsins im Glycerinauszuge wurde nach 48 Stunden entnommen. Ein mit derselben ausgeführter Versuch zeigte die Anwesenheit des fettspaltenden Fermentes. Weitere Versuche überzeugten uns, daß die Menge des in das Glycerin übergegangenen Fettfermentes im Laufe von einigen Tagen etwas anstieg, was aus der weiter unten folgenden Tabelle zu ersehen ist. Andererseits beweist dieselbe Tabelle, daß das fettspaltende Magenferment im Glycerin nicht lange haltbar ist.

Aus der Seite 58 angeführten Tabelle geht hervor, daß das

1) 1. $\mathrm{c}$.

2) 1. c. 
Lecithin durch Magensteapsin und selbst durch Magensaft, obschon weniger energisch als durch Pankreassteapsin, gespalten werden kann und zwar in gleicher Art wie durch letzteres. Diese Wirkung des Magensaftes soll nächstens noch bei anderer Gelegenheit besprochen werden. Übrigens ist vor kurzem eine Arbeit von Paul Mayer erschienen (21. Juli), welche ebenfalls die Frage nach der Spaltung der lipoiden Substanzen durch Lipase behandelt. Der Verfasser kommt bezüglich des Pankreassteapsins zu den gleichen, jedoch bezüglich des Magensteapsins zu etwas abweichenden Ergebnissen. Er findet nämlich eine viel schwächere Wirkung des letzteren als wir.

\section{Wirkung verschiedener Serolipasen auf Lecithin.}

Nachdem die schon angeführten Versuche ergeben hatten, daß das fettspaltende Ferment der Pankreasdrüse resp. des Pankreassaftes, sowie das im Magen enthaltene Steapsin befähigt sind, das Lecithin zu spalten, war es von Belang, die Lipase des Blutes resp. des Serums in gleicher Richtung zu studieren. Die diesbezüglichen Versuche ergaben ein ganz unerwartetes und auffallendes Resultat. Es erwies sich nämlich, daß die Serolipase sich gegenüber Lecithin abweichend verhält, $d . h$. nicht imstande ist, das Lecithin zu spalten, resp. die Fettsäuren aus ihm in Freiheit zu setzen, was daraus zu schließen war, daß die Reaktion des Gemisches bei Einwirkung von verschiedenen Blutlipasen auf Lecithin unverändert bleibt. Dieses bemerkenswerte Verhalten der Blutlipase gegenüber dem Lecithin zeigten Serolipasen verschiedenen Ursprungs, $d . h$. von verschiedenen Tieren herstammende Lipasen waren in bezug auf die Spaltung des Lecithins gleich unwirksam. Es wurden folgende Serolipasen in der erwähnten Richtung untersucht: vom Schaf, Hund und Pferd, Kaninchen, Aal (als die stärkste bis dahin bekannte Serolipase überhaupt). Keine von den eben genannten Lipasen war imstande, auch nur eine geringe spaltende Wirkung auf das Lecithin auszuüben; obgleich wir in vielen Versuchen bedeutende, 3-5fache Mengen der Serolipase zum Versuch verwandten und die Einwirkungszeit im Thermostaten verlängerten, war der Erfolg stets ein gleich negativer. 
Tabelle

Zerlegung des Lecithins

Säuregrad in Kabikzentimetern der zur

\begin{tabular}{|c|c|c|c|c|}
\hline \multirow{2}{*}{ Versuchsanordnung } & \multicolumn{2}{|c|}{$\begin{array}{c}\text { Reaktion des Gemisches } \\
\text { vor der Einwirkung } \\
\text { des Fermentes }\end{array}$} & \multicolumn{2}{|c|}{$\begin{array}{c}\text { Reaktion des Gemisches } \\
\text { nach Zusatz von auf } 72^{\circ} \\
\text { erwärmtem Ferment }\end{array}$} \\
\hline & $\begin{array}{l}\text { Titration in } \\
\text { wässeriger } \\
\text { Lösuug }\end{array}$ & $\begin{array}{c}\text { Titration in } \\
\text { alkoholischer } \\
\text { Lösung }\end{array}$ & $\begin{array}{l}\text { Titration in } \\
\text { wässeriger } \\
\text { Lösung }\end{array}$ & $\begin{array}{c}\text { Titration in } \\
\text { alkoholischer } \\
\text { Lösung }\end{array}$ \\
\hline \multirow{2}{*}{$\begin{array}{l}5 \mathrm{ccm} \text { Lecithinemulsion } \\
+1 \mathrm{ccm} 2 \times 24 \text { Stunden } \\
\text { extrahierter Glycerin- } \\
\text { auszug des Hundemagens }\end{array}$} & 2,2 & 6,2 & 2,1 & 6,0 \\
\hline & 2,4 & 6,2 & 2,4 & 6,1 \\
\hline \multirow{2}{*}{$\begin{array}{l}5 \text { ccm Lecithinemulsion } \\
+2 \text { ccm } 2 \times 24 \text { Stunden } \\
\text { extrahierter Glycerin- } \\
\text { auszug des Hundemagens }\end{array}$} & 2,8 & 6,1 & 2,8 & 6,1 \\
\hline & 2,7 & 6,2 & 2,6 & 6,1 \\
\hline \multirow{2}{*}{$\begin{array}{l}5 \mathrm{ccm} \text { Lecithinemulsion } \\
+1 \mathrm{ccm} 5 \times 24 \text { Stunden } \\
\text { extrahierter Glycerin- } \\
\text { auszug des Hundemagens }\end{array}$} & 1,7 & 2,7 & 1,6 & 2,6 \\
\hline & 1,75 & 2,6 & 1,7 & 2,7 \\
\hline \multirow{2}{*}{$\begin{array}{c}5 \text { ccm Lecithinemulsion } \\
+2 \mathrm{ccm} 5 \times 24 \text { Stunden } \\
\text { extrahierter Glycerin-1 } \\
\text { auszug des Hundemagens }\end{array}$} & 1,9 & 3,2 & 1,9 & 3,4 \\
\hline & 2,0 & 3,3 & 2,0 & 3,2 \\
\hline \multirow{2}{*}{$\begin{array}{l}5 \text { ccm Lecithinemulsion } \\
+0,5 \mathrm{ccm} 5 \times 24 \text { Stunden } \\
\text { extrahierter Glycerin- } \\
\text { auszug des Hundemagens }\end{array}$} & 1,7 & 5,1 & 1,6 & $\check{5}, 0$ \\
\hline & 1,6 & 5,0 & 1,5 & $\check{5}, 0$ \\
\hline \multirow{2}{*}{$\begin{array}{l}5 \mathrm{ccm} \text { Lecithinemulsion } \\
+0,5 \mathrm{ccm} 5 \times 24 \text { Stunden } \\
\text { extrahierter Glycerin-; } \\
\text { auszug des Hundemagens }\end{array}$} & 1,6 & 4,9 & 1,6 & 4,8 \\
\hline & 1,5 & $\dot{5}, 0$ & 1,5 & 5,0 \\
\hline
\end{tabular}

$5 \times 24$ Stunden extrahierter gleicher Glycerinauszug aus

$5 \mathrm{ccm}$ Lecithinemulsion $+1 \mathrm{ccm} 5 \times 24$ Stunden extrahierter Glycerinauszug des Hundemagens

\begin{tabular}{l|l}
1,9 & 3,2 \\
1,7 & 3,1
\end{tabular}

\begin{tabular}{l|l|}
3,2 & 1,9 \\
3,1 & 1,7
\end{tabular}

3,1

3,1

$5 \mathrm{ccm}$ Lecithinemulsion $+2 \mathrm{ccm}$ Magensaft

5 ccm Lecithinemulsion $+4 \mathrm{ccm}$ Magensaft

\begin{tabular}{l|l}
2,4 & 3,8 \\
2,5 & 3,6 \\
6,8 & 9,2 \\
6,9 & 9,0
\end{tabular}

Hunde- 
Ir. III.

urch Hundemagensteapsin.

eutralisation gebrauchten 1/20 $\mathrm{n}$-KHO.

Reaktion des Gemisches mit auf $72^{\circ}$ erwärmtem Ferment nach 24 st. Verweilen im Thermostaten

Titration in Titration in wässeriger alkoholischer Lösung
Reaktion des Gemisches nach 24stündigem Verweilen im Thermostaten
Aciditätszuwachs in Kubikzentimetern $1 / 20-\mathrm{KOH}$ ausgedrückt Titration in Titration in Titration in Titration in wässeriger alkoholischer wässeriger alkoholischer Lösung Lösung
Lösung
Lösung

\begin{tabular}{l|l|l|l|l|l}
2,1 & 6,1 & 3,0 & 8,9 & $\mathbf{0 , 8}$ & $\mathbf{2 , 7}$ \\
2,5 & 6,2 & 3,3 & 9,4 & $\mathbf{0 , 9}$ & $\mathbf{3 , 2}$ \\
2,7 & 6,0 & 4,3 & 9,8 & $\mathbf{1 , 5}$ & $\mathbf{3 , 7}$ \\
2,6 & 6,2 & 4,4 & 10,0 & $\mathbf{1 , 7}$ & $\mathbf{3 , 8}$ \\
1,8 & 2,8 & 4,8 & 7,1 & $\mathbf{3 , 1}$ & $\mathbf{4 , 4}$ \\
1,7 & 2,6 & 4,8 & 7,2 & $\mathbf{3 , 0 5}$ & $\mathbf{4 , 6}$ \\
1,9 & 3,2 & 5,5 & 7,7 & $\mathbf{3 , 6}$ & $\mathbf{4 , 5}$ \\
2,1 & 3,2 & 5,8 & 7,9 & $\mathbf{3 , 8}$ & $\mathbf{4 , 6}$ \\
$1,6 \check{0}$ & 5,0 & 2,2 & 6,5 & $\mathbf{0 , 5}$ & $\mathbf{1 , 4}$ \\
1,6 & 5,0 & 2,0 & 6,3 & $\mathbf{0 , 4}$ & $\mathbf{1 , 3}$ \\
1,6 & 4,9 & 1,9 & 6,0 & $\mathbf{0 , 3}$ & $\mathbf{1 , 1}$ \\
1,5 & 5,0 & 1,8 & 6,0 & $\mathbf{0 , 3}$ & $\mathbf{1 , 0}$
\end{tabular}

IIagen bei Zimmertemperatur 10 Tage aufbewahrt.

\begin{tabular}{l|l|l|l|l|l}
1,9 & 3,1 & 3,3 & 6,4 & 1,4 & 3,2 \\
1,7 & 3,1 & 3,5 & 6,2 & 1,8 & 3,1
\end{tabular}

nagensaft.

\begin{tabular}{l|l|l|l|l|l|r}
2,3 & 3,6 & 3,3 & 5,0 & $\mathbf{0 , 7}$ & $\mathbf{1 , 2}$ \\
2,4 & 3,6 & $\mathbf{3 , 5}$ & $\mathbf{5 , 1}$ & $\mathbf{1 , 0}$ & $\mathbf{1 , 5}$ \\
6,7 & 9,2 & $8, \mathbf{5}$ & 11,4 & $\mathbf{1 , 5}$ & $\mathbf{2 , 2}$ \\
6,9 & 9,0 & 8,6 & 11,3 & $\mathbf{1 , 7}$ &
\end{tabular}


Tabelle Nr. IV. Wirkung

Säuregrad in Kubikzentimetern der zur

\begin{tabular}{|c|c|c|c|c|}
\hline \multirow{2}{*}{ Versuchsanordnung } & \multicolumn{2}{|c|}{$\begin{array}{l}\text { Reaktion des Gemisches } \\
\text { vor der Einwirkung } \\
\text { der Serolipase }\end{array}$} & \multicolumn{2}{|c|}{$\begin{array}{c}\text { Reaktion des Gemisches } \\
\text { nach Zusatz von auf } 72^{\circ} \\
\text { erwärmter Serolipase }\end{array}$} \\
\hline & $\begin{array}{l}\text { Titration in } \\
\text { wässeriger } \\
\text { Lösung }\end{array}$ & $\left|\begin{array}{c}\text { Titration in } \\
\text { alkoholischer } \\
\text { Lösung }\end{array}\right|$ & $\begin{array}{c}\text { Titration in } \\
\text { wässeriger } \\
\text { Lösung }\end{array}$ & $\begin{array}{c}\text { Titration in } \\
\text { alkoholischer } \\
\text { Lösung }\end{array}$ \\
\hline $\begin{array}{l}5 \mathrm{ccm} \text { Lecithinemulsion }+1 \mathrm{ccm} \\
\text { Kaninchen-Serolipase }\end{array}$ & $\begin{array}{l}1,25 \\
1,3\end{array}$ & $\begin{array}{l}2,1 \\
2,4\end{array}$ & $\begin{array}{l}1,25 \\
1,3\end{array}$ & $\begin{array}{l}2,1 \\
2,4\end{array}$ \\
\hline $\begin{array}{c}5 \mathrm{ccm} \text { Lecithinemulsion }+2 \mathrm{ccm} \\
\text { Kaninchen-Serolipase }\end{array}$ & $\begin{array}{l}1,5 \\
1,4\end{array}$ & $\begin{array}{l}3,2 \\
3,0\end{array}$ & $\begin{array}{l}1,5 \\
1,3\end{array}$ & $\begin{array}{l}3,1 \\
3,0\end{array}$ \\
\hline $\begin{array}{c}5 \mathrm{ccm} \text { Lecithinemulsion }+1 \mathrm{ccm} \\
\text { Hunde-Lipase }\end{array}$ & $\begin{array}{l}1,45 \\
1,6\end{array}$ & $\begin{array}{l}2,6 \\
2,8\end{array}$ & $\begin{array}{l}1,5 \\
1,6\end{array}$ & $\begin{array}{l}2,6 \\
2,7\end{array}$ \\
\hline $\begin{array}{c}5 \mathrm{ccm} \text { Lecithinemulsion }+5 \mathrm{ccm} \\
\text { Hunde-Lipase }\end{array}$ & $\begin{array}{l}1,8 \\
1,9\end{array}$ & $\begin{array}{l}2,8 \\
3,0\end{array}$ & $\begin{array}{l}1,7 \\
1,9\end{array}$ & $\begin{array}{l}2,8 \\
3,1\end{array}$ \\
\hline $\begin{array}{c}5 \mathrm{ccm} \text { Lecithinemulsion }+3 \mathrm{ccm} \\
\text { Serolipase vom Schaf }\end{array}$ & $\begin{array}{l}1,1 \\
1,2\end{array}$ & $\begin{array}{l}1,6 \\
1,7\end{array}$ & $\begin{array}{l}1,0 \\
1,1\end{array}$ & $\begin{array}{l}1,5 \\
1,6\end{array}$ \\
\hline $\begin{array}{c}5 \mathrm{ccm} \text { Lecithinemulsion }+5 \mathrm{ccm} \\
\text { Serolipase vom Schaf }\end{array}$ & $\begin{array}{l}1,5 \\
1,6\end{array}$ & $\begin{array}{l}1,9 \\
1,8\end{array}$ & $\begin{array}{l}1,5 \\
1,6\end{array}$ & $\begin{array}{l}1,9 \\
1,8\end{array}$ \\
\hline $\begin{array}{c}5 \mathrm{ccm} \text { Lecithinemulsion }+1 \mathrm{ccm} \\
\text { Serolipase vom Pferd }\end{array}$ & $\begin{array}{l}2,2 \\
2,3\end{array}$ & $\begin{array}{l}4,4 \\
4,4\end{array}$ & $\begin{array}{l}2,3 \\
2,3\end{array}$ & $\begin{array}{l}4,3 \\
4,3\end{array}$ \\
\hline $\begin{array}{c}5 \mathrm{ccm} \text { Lecithinemulsion }+2 \mathrm{ccm} \\
\text { Serolipase vom Pferd }\end{array}$ & $\begin{array}{l}4,2 \\
4,1\end{array}$ & $\begin{array}{l}5,0 \\
5,0\end{array}$ & $\begin{array}{l}4,2 \\
4,1\end{array}$ & $\begin{array}{l}4,9 \\
5,0\end{array}$ \\
\hline $\begin{array}{c}5 \mathrm{ccm} \text { Lecithinemulsion }+3 \mathrm{ccm} \\
\text { Serolipase vom Pferd }\end{array}$ & $\begin{array}{l}4,5 \\
4,6\end{array}$ & $\begin{array}{l}7,4 \\
7,5\end{array}$ & $\begin{array}{l}4,3 \\
4,5\end{array}$ & $\begin{array}{l}7,3 \\
7,5\end{array}$ \\
\hline $\begin{array}{c}5 \mathrm{ccm} \text { Lecithinemulsion }+5 \mathrm{ccm} \\
\text { Serolipase vom Pferd }\end{array}$ & $\begin{array}{l}4,8 \\
4,9\end{array}$ & $\begin{array}{l}8,5 \\
8,7\end{array}$ & $\begin{array}{l}4,8 \\
4,9\end{array}$ & $\begin{array}{l}8,5 \\
8,6\end{array}$ \\
\hline $\begin{array}{c}5 \mathrm{ccm} \text { Lecithinemulsion }+2 \mathrm{ccm} \\
\text { Serolipase vom Aal }\end{array}$ & $\begin{array}{l}0,9 \\
1,2\end{array}$ & $\begin{array}{l}1,9 \\
2,0\end{array}$ & $\begin{array}{l}0,9 \\
1,2\end{array}$ & $\begin{array}{l}1,9 \\
2,0\end{array}$ \\
\hline $\begin{array}{l}5 \mathrm{ccm} \text { Lecithinemulsion }+5 \mathrm{ccm} \\
\text { Serolipase vom Aal }\end{array}$ & $\begin{array}{l}1,5 \\
1,4\end{array}$ & $\begin{array}{l}2,4 \\
2,6\end{array}$ & $\begin{array}{l}1,5 \\
1,4\end{array}$ & $\mid \begin{array}{l}2,3 \\
2,7\end{array}$ \\
\hline $5 \mathrm{ccm}$ Monobutyrin $+1 \mathrm{ccm}$ Sero- & 1,1 & 1,2 & $\begin{array}{l}\text { Wirkung } \\
1.1\end{array}$ & der Serolipase \\
\hline lipase vom Pferd & 1,2 & $\begin{array}{l}1,2 \\
1,1\end{array}$ & $\begin{array}{l}1,1 \\
1,2\end{array}$ & $\begin{array}{l}1,1 \\
1,2\end{array}$ \\
\hline $\begin{array}{l}5 \mathrm{ccm} \text { Monobutyrin }+2 \mathrm{ccm} \text { Sero- } \\
\text { lipase vom Pferd auf } 72^{\circ} \text { erwärmt }\end{array}$ & 1,3 & 1,6 & 1,3 & 1,6 \\
\hline $\begin{array}{l}5 \mathrm{ccm} \text { Äthylbutyrat }+1 \mathrm{ccm} \text { Sero- } \\
\text { lipase vom Pferd }\end{array}$ & $\begin{array}{l}0,8 \\
0,7\end{array}$ & $\begin{array}{l}1,1 \\
1,2\end{array}$ & $\begin{array}{l}0,8 \\
0,7\end{array}$ & $\begin{array}{l}1,0 \\
1,2\end{array}$ \\
\hline $\begin{array}{l}5 \mathrm{ccm} \text { Äthylbutyrat }+3 \mathrm{ccm} \text { Sero- } \\
\text { lipase vom Pferd auf } 72^{\circ} \text { erwärmt } \\
\text {.. }\end{array}$ & 1,2 & 1,7 & 1,1 & 1,6 \\
\hline $\begin{array}{l}5 \mathrm{ccm} \text { Äthylbutyrat }+5 \mathrm{ccm} \text { Sero- } \\
\text { lipase vom Pferd auf } 72^{\circ} \text { erwärmt }\end{array}$ & 1,5 & 1,9 & 1,5 & 1,8 \\
\hline $\begin{array}{c}5 \mathrm{ccm} \text { Monobutyrin }+0,5 \mathrm{ccm} \\
\text { Serolipase vom Aal }\end{array}$ & $\begin{array}{l}1,7 \\
1,5\end{array}$ & $\begin{array}{l}2,0 \\
1,9\end{array}$ & - & - \\
\hline $\begin{array}{l}5 \mathrm{ccm} \text { Äthylbutyrat }+0,5 \mathrm{ccm} \\
\text { Serolipase vom Aal }\end{array}$ & 2,4 & $\begin{array}{l}\text { Brought to } \\
2,6 \\
2,3\end{array}$ & d Date | & $\left|\begin{array}{l}\text { University } \\
\text { ated - } \\
\text { 25/15T:30 A }\end{array}\right|$ \\
\hline
\end{tabular}


3r Serolipase auf Lecithin.

eutralisation gebrauchten $1 / 2$ n-KHO.

Reaktion des Gemisches mit auf $72^{\circ}$ erwärmtem Ferment nach 24st. Verweilen im Thermostaten

\begin{tabular}{|c|c|c|c|c|c|}
\hline \multicolumn{2}{|c|}{ 24st. Verweilen im Thermostaten } & \multicolumn{2}{|c|}{ weilen im Thermostaten } & \multicolumn{2}{|c|}{ ausgedrückt } \\
\hline $\begin{array}{l}\text { Titration } \\
\text { in wässeriger } \\
\text { Lösung }\end{array}$ & $\begin{array}{c}\text { Titration } \\
\text { in alkoholischer } \\
\text { Lösung }\end{array}$ & $\begin{array}{l}\text { Titration in } \\
\text { wässeriger } \\
\text { Lösung }\end{array}$ & $\begin{array}{c}\text { Titration in } \\
\text { alkoholischer } \\
\text { Lösung }\end{array}$ & $\begin{array}{l}\text { Titration in } \\
\text { wässeriger } \\
\text { Lösung }\end{array}$ & $\begin{array}{l}\text { Titration in } \\
\text { alkoholischer } \\
\text { Lösung }\end{array}$ \\
\hline $\begin{array}{l}1,23 \\
1,2\end{array}$ & $\begin{array}{l}2,0 \\
2,3\end{array}$ & $\begin{array}{l}1,24 \\
1,26\end{array}$ & $\begin{array}{l}2,1 \\
2,4\end{array}$ & $\begin{array}{l}0 \\
0\end{array}$ & $\begin{array}{l}0 \\
0\end{array}$ \\
\hline $\begin{array}{l}1,5 \\
1,4\end{array}$ & $\begin{array}{l}3,1 \\
3,0\end{array}$ & $\begin{array}{l}1,5 \\
1,4\end{array}$ & $\begin{array}{l}3,1 \\
3,0\end{array}$ & $\begin{array}{l}0 \\
0\end{array}$ & $\begin{array}{l}0 \\
0\end{array}$ \\
\hline $\begin{array}{l}1,4 \\
1,6\end{array}$ & $\begin{array}{l}2,5 \\
2,7\end{array}$ & $\begin{array}{l}1,4 \\
1,6\end{array}$ & $\begin{array}{l}2,5 \\
2,7\end{array}$ & $\begin{array}{l}0 \\
0\end{array}$ & $\begin{array}{l}0 \\
0\end{array}$ \\
\hline $\begin{array}{l}1,8 \\
1,9\end{array}$ & $\begin{array}{l}2,7 \\
3,0\end{array}$ & $\begin{array}{l}1,8 \\
1,8\end{array}$ & $\begin{array}{l}2,8 \\
3,0\end{array}$ & $\begin{array}{l}0 \\
0\end{array}$ & $\begin{array}{l}0 \\
0\end{array}$ \\
\hline $\begin{array}{l}1,0 \\
1,2\end{array}$ & $\begin{array}{l}1,6 \\
1,7\end{array}$ & $\begin{array}{l}1,1 \\
1,2\end{array}$ & $\begin{array}{l}1,4 \\
1,7\end{array}$ & $\begin{array}{l}0 \\
0\end{array}$ & $\begin{array}{l}0 \\
0 .\end{array}$ \\
\hline $\begin{array}{l}1,5 \\
1,6\end{array}$ & $\begin{array}{l}1,9 \\
1,8\end{array}$ & $\begin{array}{l}1,5 \\
1,6\end{array}$ & $\begin{array}{l}1,9 \\
1,8\end{array}$ & $\begin{array}{l}0 \\
0\end{array}$ & $\begin{array}{l}0 \\
0\end{array}$ \\
\hline $\begin{array}{l}2,2 \\
2,3\end{array}$ & $\begin{array}{l}4,4 \\
4,3\end{array}$ & $\begin{array}{l}2,2 \\
2,3\end{array}$ & $\begin{array}{l}4,3 \\
4,4\end{array}$ & $\begin{array}{l}0 \\
0\end{array}$ & $\begin{array}{l}0 \\
0\end{array}$ \\
\hline $\begin{array}{l}4,2 \\
4,0\end{array}$ & $\begin{array}{l}4,9 \\
5,0\end{array}$ & $\begin{array}{l}4,0 \\
4,1\end{array}$ & $\begin{array}{l}4,8 \\
5,0\end{array}$ & $\begin{array}{l}0 \\
0\end{array}$ & $\begin{array}{l}0 \\
0\end{array}$ \\
\hline $\begin{array}{l}4,3 \\
4,6\end{array}$ & $\begin{array}{l}7,4 \\
7,4\end{array}$ & $\begin{array}{l}4,2 \\
4,6\end{array}$ & $\begin{array}{l}7,3 \\
7,6\end{array}$ & $\begin{array}{l}0 \\
0\end{array}$ & $\begin{array}{l}0 \\
0\end{array}$ \\
\hline 4,8 & 8,7 & $\begin{array}{l}4,8 \\
4,8\end{array}$ & $\begin{array}{l}8,5 \\
8,7\end{array}$ & $\begin{array}{l}0 \\
0\end{array}$ & $\begin{array}{l}0 \\
0\end{array}$ \\
\hline $\begin{array}{l}0,8 \\
1,1\end{array}$ & $\begin{array}{l}1,9 \\
1,9\end{array}$ & $\begin{array}{l}0,9 \\
1,1\end{array}$ & $\begin{array}{l}1,9 \\
1,9\end{array}$ & $\begin{array}{l}0 \\
0\end{array}$ & $\begin{array}{l}0 \\
0\end{array}$ \\
\hline $\begin{array}{l}1, \tilde{0} \\
1,4\end{array}$ & $\begin{array}{l}2,4 \\
2,6\end{array}$ & $\begin{array}{l}1,6 \\
1,4\end{array}$ & $\begin{array}{l}2,3 \\
2,7\end{array}$ & $\begin{array}{l}0 \\
0\end{array}$ & $\begin{array}{l}0 \\
0\end{array}$ \\
\hline
\end{tabular}

auf künstliches Fett.

\begin{tabular}{c|c|c}
1,0 & 1,1 & 2,5 \\
1,1 & 1,2 & 2,6 \\
1,2 & 1,5 & 1,3 \\
1,8 & 1,1 & 3,9 \\
0,8 & 1,2 & 3,7 \\
1,1 & 1,6 & 1,2 \\
1,4 & 1,8 & 1,5 \\
- & - & 3,1 \\
- & - & 3,3 \\
- & - & 4,8 \\
- & - & 4,7
\end{tabular}

Reaktion des Gemisches nach 24stündigem Verreilen im Thermostaten

Aciditätszuwachs in

ubikzentimetern $1 / 2 \mathrm{n}-\mathrm{KHO}$ ausgedrückt

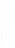


Das Verhalten des fettspaltenden Blutfermentes, d. h. der Serolipase gegenüber Lecithin ist in vieler Hinsicht bemerkenswert, besonders aber deswegen, weil bekanntlich das Lecithin einen nie fehlenden Bestandteil der Blutkörperchen, folglich des Blutes bildet und weil vielleicht ein entgegengesetztes Verhalten der Lipase zum Lecithin zu bedeutenden Störungen, sogar zum Tode führen könnte. Andererseits nimmt durch das abweichende Verhalten gegenüber dem Lecithin die Serolipase eine Sonderstellung gegenüber den bis dahin bekannten fettspaltenden Fermenten ein. Dadurch wird die Frage nach der Provenienz der Lipase, ihrer Abhängigkeit resp. ihrer vermutlichen Abstammung vom Pankreassafte ebenfalls in negativem Sinne entschieden.

Die Unwirksamkeit der Serolipase gegenüber dem Lecithin könnte natürlich auch anders gedeutet werden, und zwar könnte man annehmen, daß diese spaltende Wirkung durch die Anwesenheit eines antilipolytisch wirkenden Prinzips sozusagen durch ein Antiferment im Blute resp. Serum verhindert wird, und daß also keine prinzipielle Verschiedenheit der Funktionen von Steapsin und Lipase zu bestehen brauchte. Es ist aber bis dahin nicht möglich gewesen, durch verschiedenartige Eingriffe einen derartigen Antikörper im Blute oder Serum nachzuweisen. Andererseits haben wir durch parallele Versuche mit künstlichen Fetten, wie Monobutyrin und Äthylbutyrat, stets das Vorhandensein der lipolytischen Funktion in dem zum Versuch verwandten Präparat der Serolipase nachkontrolliert und zwar jedesmal mit positivem Ergebnis.

Außer den fettspaltenden Fermenten tierischen Ursprungs zogen wir in den Kreis unserer Untersuchung auch Fermente von entsprechender Wirkung, aber pflanzlicher Provenienz. Von pflanzlichen Fermenten verwandten wir dasjenige, welches in den Samen von Ricinus communis enthalten ist. Die Versuche wurden einerseits mit den entfetteten und von Schalen befreiten, fein zerpulverten Samen selbst, außerdem mit den aus denselben dargestellten Extrakten angestellt. Als Extraktionsmittel wandten wir physiologische Kochsalzlösung $(0,9 \%)$, welcher $5 \%$ Glycerin und 0,5\% Phenol hinzugetan war und welche sich bei 
entsprechenden Untersuchungen von Dr. Bitni-Schlachto $\left.{ }^{1}\right)$ in unserem Laboratorium als passendes Medium zur Extraktion der Lipase sich erwiesen hat, an. In beiden Fällen war das Resultat ein positives. Die Versuchsanordnung war mit der vorher beschriebenen identisch. Die Lecithinzerlegung durch das pflanzliche Ferment des Ricinussamens geht ziemlich energisch vor sich. Die erzielten Resultate nebst deren Details und Zahlenangaben sollen in der nächsten Mitteilung veröffentlicht werden. Außerdem bleibt noch festzustellen, ob das Vermögen, Lecithin zu spalten, dem fettspaltenden Ferment als solchem zukommt, oder ob eventuell in dem Pankreas- und Magensteapsin, sowie in den Pflanzen ein spezifisch auf Lecithin einwirkendes Ferment, eine «Lecithinase», resp. ein anders zu nennendes Enzym existiert.

Fassen wir unsere Resultate zusammen, so können wir folgendes konstatieren:

1. Das Lecithin wird durch Pankreas- resp. Magensteapsin gespalten.

2. Die Spaltung wird am intensivsten durch Pankreassteapsin resp. das im Pankreassafte enthaltene Steapsin, weniger energisch durch das fettspaltende Ferment des Magens und des Magensaftes hervorgerufen.

3. Pflanzliche Fermente und speziell das aus Samen von Ricinus communis dargestellte sind ebenfalls imstande, Lecithin und zwar in gleicher Weise durch Abspaltung der Fettsäuren zu zerlegen.

4. Durch das fettspaltende Ferment des Blutes oder Blutserums resp. durch die Serolipase von verschiedenen Tieren wird dagegen das Lecithin nicht angegriffen.

5. Durch dies negative Verhalten gegenüber dem Lecithin ist die Lipase von anderen lipolytisch wirkenden Euzymen zu unterscheiden.

1) Zentralblatt für Bakteriologie, 1. Abt., Bd. XXXV, S. 535.

Archives des sciences biolog., Bd. XI, S. 370. Russische Dissertation 1904 . 